\title{
Influence of Hydrothermal Processing on the Structuring of Amorphous Strontium Hydroxyapatite
}

\section{K. A. Prosolov'1,2, A. Sainova ${ }^{1}$, A. Osite ${ }^{3}$, Yu. P. Sharkeev ${ }^{1,2}$, and K. A. Gross ${ }^{4}$}

${ }^{1}$ Institute of Strength Physics and Materials Science of SB RAS, Russia, Tomsk, Academicheskii pr., 2/4, 634055

${ }^{2}$ National Research Tomsk Polytechnic University, Russia, Tomsk, Lenina pr., 30, 634050

${ }^{3}$ Department of Analytical Chemistry, University of Latvia, K. Valdemara Street 48, Riga, LV1013, Latvia

${ }^{4}$ Faculty of Materials Science and Applied Chemistry, Riga Technical University, Azenes Street 14/24, Riga, LV-1048, Latvia

\section{Abstract}

Strontium substituted hydroxyapatite is a biomaterial with high level of biocompatibility with improved cell proliferation from $\mathrm{Sr}$ ions in hydroxyapatite.

Corresponding Author:

K. A. Prosolov

konstprosolov@gmail.com

Received: 22 July 2018

Accepted: 9 September 2018

Published: 8 October 2018

Publishing services provided by

Knowledge E

(c) K. A. Prosolov et al. This article is distributed under the terms of the Creative Commons

Attribution License, which

permits unrestricted use and

redistribution provided that the

original author and source are

credited.

Selection and Peer-review under the responsibility of the Breakthrough Directions of Scientific Research at MEPhI Conference Committee.

\section{G OPEN ACCESS}

The aim of this research is to study the effect of saturated steam pressure at elevated temperature on the transitions within amorphous strontium hydroxyapatite powder. Processing temperatures and times ranged from 90 to $150^{\circ} \mathrm{C}$ for periods of 1,3 and 6 hours, respectively. Powder was characterized by X-Ray Diffraction and Fourier Transformed Infrared Spectroscopy. The appearance of diffraction peaks in the $X$-ray diffraction pattern suggested that longer processing times were necessary to transform amorphous strontium hydroxyapatite to a higher crystallinity at lower temperatures. Transition from the amorphous to the crystalline state begins at $150^{\circ} \mathrm{C}$ after an hour, at $120^{\circ} \mathrm{C}$ after 3 hours, or at $110^{\circ} \mathrm{C}$ after 6 hours. Infrared spectroscopy showed the characteristic phosphate absorption band and the presence of carbonate in the powder.

Keywords: hydrothermal processing, biomaterials, hydroxyapatite, material design, biocompatibility

\section{Introduction}

Materials based on hydroxyapatite $\left(\mathrm{Ca}_{10}\left(\mathrm{PO}_{4}\right)_{6}(\mathrm{OH})_{2}, \mathrm{HA}\right)$ and other calcium phosphates, such as dicalcium phosphate $\left(\mathrm{CaHPO}_{4}\right)$, tricalcium phosphate $\left(\mathrm{Ca}_{3}\left(\mathrm{PO}_{4}\right)_{2}\right)$, tetracalcium phosphate $\left(\mathrm{Ca}_{4}\left(\mathrm{PO}_{4}\right)_{2} \mathrm{O}\right)$, and octacalcium phosphate $\left(\mathrm{Ca}_{8} \mathrm{H}_{2}\left(\mathrm{PO}_{4}\right)_{6} \cdot 5 \mathrm{H}_{2} \mathrm{O}\right)$, have attracted tremendous interest because of the similarities with the mineral fraction of human bone tissue and their high osteoconductive potential [1]. Hydroxyapatite is biocompatible with living bone tissues and is the most widely used biomaterial from 
the calcium phosphates $[1,2]$. HA promotes increased bone bonding and is extensively used as a coating for dental and orthopedic implants. It is very stable and the least soluble among all the calcium orthophosphates at normal temperature and $\mathrm{pH}$ value ranging from 4 to 12 [3].

Nowadays, research groups in the field of bioengineering are striving to produce biomaterials with enhanced properties. In this regard, HA is the most promising material owning to its possibility to be processed and designed in a wide range of applications it includes enhanced osseointegration, antibacterial activity, etc. [4, 5]. A wide range of new properties could be achieved throughout different cationic or anionic substitutions in HA structure. Divalent cations, such as $\mathrm{Zn}, \mathrm{Fe}, \mathrm{Cu}, \mathrm{Mg}, \mathrm{Ni}, \mathrm{Cr}, \mathrm{Mn}, \mathrm{Co}, \mathrm{Sr}, \mathrm{Pb}$, and $\mathrm{Cd}$, and anions such as $\mathrm{F}^{-}, \mathrm{Cl}^{-}, \mathrm{CO}_{3}{ }^{2-}$, and $\mathrm{VO}_{4}{ }^{3-}$ may substitute for $\mathrm{Ca}^{2+}, \mathrm{OH}^{-}$, and $\left(\mathrm{PO}_{4}\right)^{3-}$ in the HA structure. These substitutions modify its thermal stability, solubility and textural properties as well as the surface reactivity. Among these substitutions, the biological role of strontium as a doping element in $\mathrm{HA}$ is well known [6].

Strontium is also believed to play an important role in the enhancement of bone remineralization that is associated with a reduction of bone resorption, an increase in the formation of new bone fracture [7-9]. Recently, strontium substituted hydroxyapatite has shown to hold great potential for coating titanium implants and as a filler for bone cements and toothpastes. Strontium hydroxyapatite (SrHA), a bioactive bone cement that is used in spinal and bone fracture surgery and also finds application in bone replacement, bone fillings, bone adhesives and for treatment of osteoporosis [10]. Synthesized Sr-doped ACP powder by wet synthesis, and prepared Sr-doped calcium phosphate cement has potential for use as a new type of bone substitute [11].

Hydrothermal treatment (HT) has been found to be one of the best methods to synthesize highly crystalline HA with homogeneous grain size at decreased processing temperatures. On the other hand, HT attracts much attention in recent years as a replacement for the high-temperature plasma spraying process in the field of coating deposition [12]. However, an effect of HT on SrHA powder has not yet been studied.

In this article, we present a way of modifying the material structure of a SrHA powder by HT. In particular, we aim to introduce a new approach to HT of calcium phosphates in the presence of increased temperature and saturated water steam which could result in amorphous to crystalline phase transition at decreased temperatures and introduction of new material properties. Conventional methods of calcium phosphate processing include methods such as precipitation of apatite in aqueous solutions, hydrolysis of phosphates in water, high temperature annealing $[13,14]$. HT could be considered as an alternative to the more conventional methods of modifying the structure of calcium 
phosphates. In this work, SrHA was treated hydrothermally under pressure at different temperatures $\left(90^{\circ} \mathrm{C}, 100^{\circ} \mathrm{C}, 110^{\circ} \mathrm{C}, 120^{\circ} \mathrm{C}, 130^{\circ} \mathrm{C}\right.$ and $\left.150^{\circ} \mathrm{C}\right)$ and processing time $(1 \mathrm{~h}, 3 \mathrm{~h}$, $6 \mathrm{~h})$.

\section{Materials and Methods}

\subsection{Synthesis of strontium-doped hydroxyapatite}

SrHA $\left(\mathrm{Ca}_{10-x} \mathrm{Sr}_{x}\left(\mathrm{PO}_{4}\right)_{6}(\mathrm{OH})_{2}\right.$, where $\left.\mathrm{x}=8\right)$ was obtained by wet-chemical precipitation method using two solutions. Solution A was prepared from $0.02 \mathrm{~mol}$ of $\mathrm{Ca}\left(\mathrm{NO}_{3}\right)_{2} \cdot 4 \mathrm{H}_{2} \mathrm{O}$, $0.06 \mathrm{~mol}$ of $\mathrm{Sr}\left(\mathrm{NO}_{3}\right)_{2}$, and $\mathrm{NH}_{3}$ water solution, solution $\mathrm{B}$ consisted of $0.03 \mathrm{~mol}$ of $\left(\mathrm{NH}_{4}\right)_{2} \mathrm{HPO}_{4}$ and $\left(\mathrm{NH}_{4}\right)_{2} \mathrm{CO}_{3}$. Analytical grade chemicals were dissolved in deionized water and the two solutions mixed, the obtained suspension was stirred for 10 minutes, washed, filtered and dried according to well-established method [15].

\subsection{Hydrothermal processing of strontium doped hydroxyapatite}

SrHA was treated in hydrothermal vessels with deionized water. For this process, 0.059 of SrHA was placed in a glass container where the powder was mixed with a magnetic stirrer bar. The glass container was placed in a Teflon vessel with $4 \mathrm{ml}$ of deionized water $\left(\mathrm{H}_{2} \mathrm{O}\right)$. Then, teflon vessel was inserted in stainless steel container, tightly closed and the HT unit was heated on the laboratory heater. The hydrothermal process was performed at different temperatures $\left(90^{\circ} \mathrm{C}, 100^{\circ} \mathrm{C}, 110^{\circ} \mathrm{C}, 120^{\circ} \mathrm{C}, 130^{\circ} \mathrm{C}\right.$, and $\left.150^{\circ} \mathrm{C}\right)$ for 1 , 3 and 6 hours.

\subsection{Characterization of processed strontium doped hydroxyapatite}

X-ray powder diffraction (XRD) was used to study the effect of hydrothermal processing on the structure of SrHA. XRD of untreated powder together with post processed SrHA was performed in order to determine initial powder state and annealing time and temperature regime needed for material phase transition. This analysis was performed on a Bruker D8 ADVANCE (Germany) diffractometer. Diffraction patterns were recorded in the $2 \theta$ range of $5^{-60^{\circ}}$ using Cu K $\alpha$ radiation $(\lambda=1.54180 \AA$ generated at $40 \mathrm{~mA}$ and $40 \mathrm{kV}$ ) at a $0.1^{\circ}$ step size. 
Fourier transform infrared (FTIR) spectroscopy was used to analyze obtained phases and chemical bonds in SrHA. The analysis was performed with Perkin Elmer Frontier spectrometer (USA) in the range of wavenumber $4000-600 \mathrm{~cm}^{-1}$.

\section{Results and Discussion}

Isochronal studies were conducted to determine the temperature of transition from an amorphous phase. The results are shown for $1 \mathrm{~h}, 3 \mathrm{~h}$ and $6 \mathrm{~h}$ of processing time, Figure 1. XRD patterns of initial SrHA is represented by two broad peaks at $2 \theta$ angles of $30^{\circ}$ and $45^{\circ}$. From this, it could be concluded that initial powder is amorphous. XRD patterns obtained for SrHA powder processed at different temperatures for 1 hour shows that $\mathrm{HT}$ at the temperatures ranging from $90^{\circ} \mathrm{C}$ to $130^{\circ} \mathrm{C}$ powders did not appear to change the amorphous state (Figure 1(a)). From the sharpening of a main peak situated at $2 \Theta$ angle of $30^{\circ}$ it could be deduced that SrHA powder begins to crystallize at $150^{\circ} \mathrm{C}$ when treated for 1 hour. When processing time is increased to 3 hours of hydrothermal treatment (Figure 1(b)) crystallization of the powder begins from a temperature of $120^{\circ} \mathrm{C}$. Higher temperatures of $130^{\circ} \mathrm{C}$ and $150^{\circ} \mathrm{C}$ clearly provide a significant change in the crystallinity. Analysis of the XRD data indicates that the main crystallographic phase was determined as $\mathrm{Ca}_{2} \mathrm{Sr}_{8}\left(\mathrm{PO}_{4}\right)_{6}(\mathrm{OH})_{2}$.
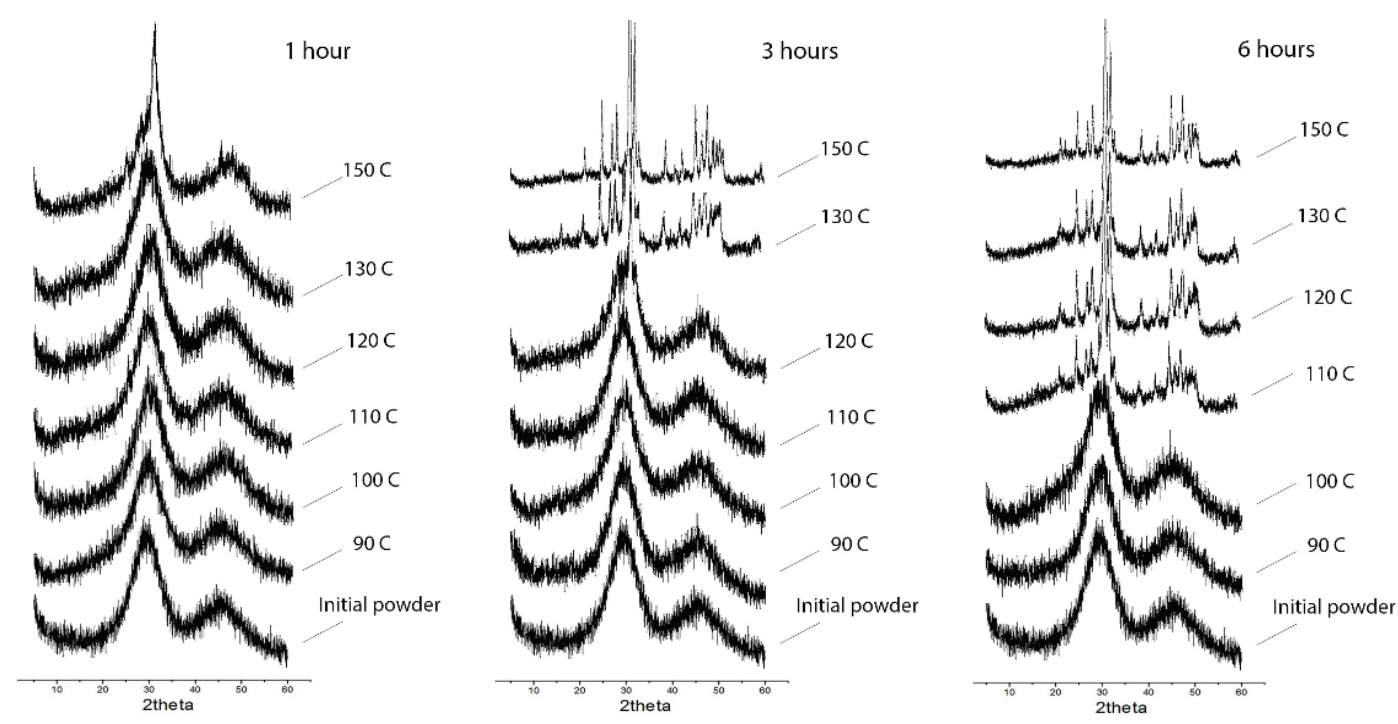

Figure 1: XRD patterns of hydrothermally treated powders for 1 (a), 3 (b) and 6 hours (c).

When the HT occurs at twice the time and takes 6 hours instead of 3 hours, crystallization occurs at even lower temperatures of $110^{\circ} \mathrm{C}$. The transition at the lower temperature of $110^{\circ} \mathrm{C}$ retains some amorphous phase, Figure $1(\mathrm{C})$. At $150^{\circ} \mathrm{C}$, the background is 


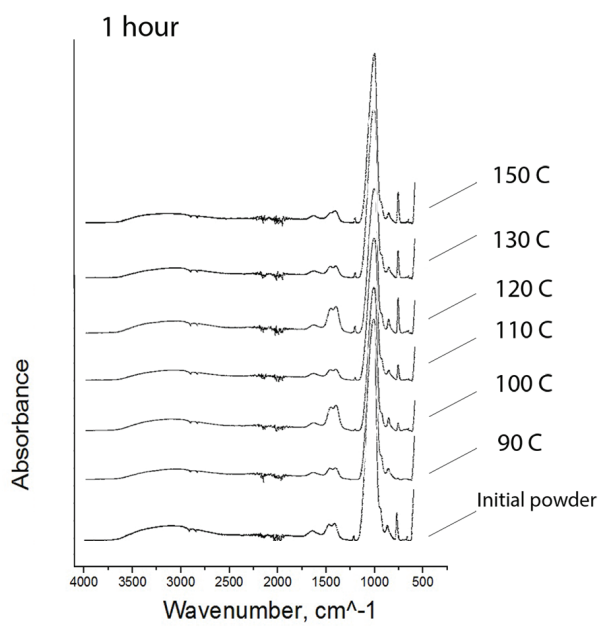

a

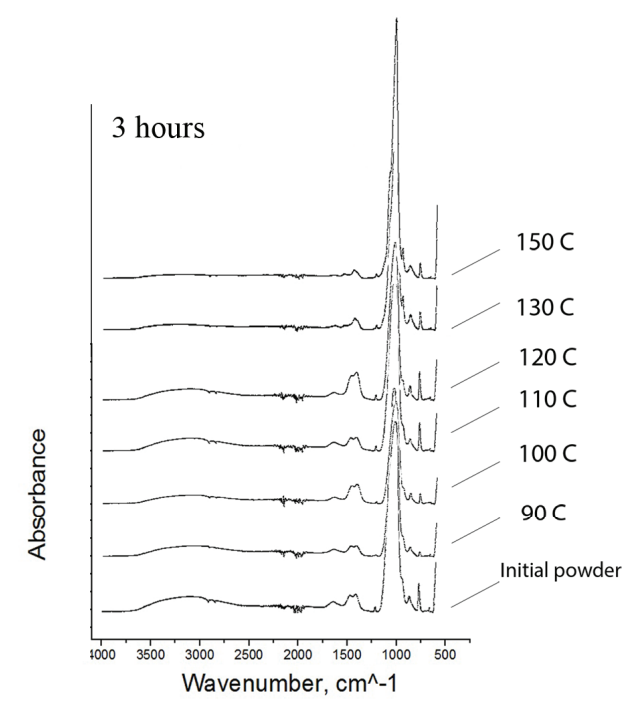

b

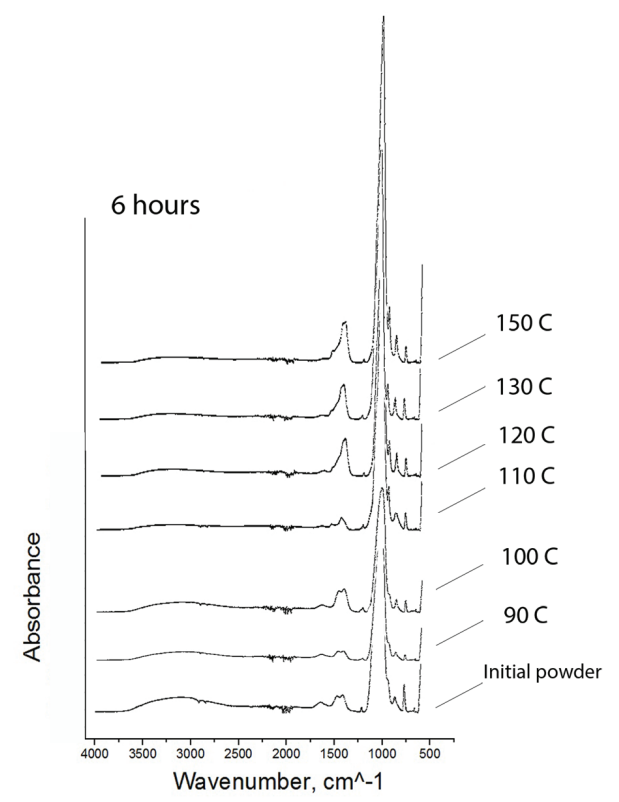

Figure 2: FTIR spectra for hydrothermally treated powders for 1 (a), 3 (b) and 6 hours (c). 
lower suggesting a low amount of retained amorphous phase. In contrast, conventional method crystallization of SrHA is annealing in air at high temperatures. The amorphous to crystalline transition for SrHA is usually performed in the temperature range from 400 to $600^{\circ} \mathrm{C}$ in a muffle furnace [16]. The use of two sources of energy - pressure and temperature - crystallizes SrHA at lower temperatures by utilizing $\mathrm{HT}$ in an environment of steam.

The FTIR spectra for SrHA powder is shown in the same format as for the XRD patterns. The highest absorbance peak at the range of wavenumbers $950-1200 \mathrm{~cm}^{-1}$ belongs to phosphate group $\mathrm{PO}_{4}^{2-}$. It can be noticed that this peak is more intense for initial powders' state in contrast to powder processed at $90^{\circ} \mathrm{C}, 100^{\circ} \mathrm{C}$ and $110^{\circ} \mathrm{C}$ in case of 1,3 and 6 hours of treatment.

According to P. Regnier et al. [17], it is now widely accepted that $\mathrm{CO}_{3}{ }^{2-}$ substitutes either for the column anions $\mathrm{OH}^{-}$or for $\mathrm{PO}_{4}{ }^{3-}$ ions in the apatite structure. This substitution in two different crystallographic sites results in two sets of absorption bands corresponding to type $\mathrm{A} \mathrm{CO}_{3}{ }^{2-}$ substitution (1540-1460-878 $\mathrm{cm}^{-1}$ ) and type $\mathrm{B}$ $\mathrm{CO}_{3}{ }^{2-}$ substitution $\left(1455-1420-871 \mathrm{~cm}^{-1}\right)$. An extensive review of the literature shows, however, that the precise IR peak positions vary sometimes significantly. It is clearly seen that peak of hydroxyl group in the HA lattice is present nearly for all spectra (1630 $\mathrm{cm}^{-1}$ ). Absorbance peak for $\mathrm{PO}_{4}{ }^{3-}$ group became sharper with higher temperatures, and more intense with a longer time of treatment. At range of wavenumbers 2750$3500 \mathrm{~cm}^{-1}$ and $1650 \mathrm{~cm}^{-1}$ adsorbed $\mathrm{OH}^{-}$group region is situated. A small peak on the range $2750-3500 \mathrm{~cm}^{-1}$ is visible for initial state, but disappears with the increase of temperature in case of 3 and 6 hours of powder processing. Characteristic absorbance peak of $\mathrm{HA}$ structural $\mathrm{OH}^{-}$bond usually located at 3573 or $3620 \mathrm{~cm}^{-1}$ is not present for all types of SrHA.

\section{Conclusion}

SrHA was successfully synthesized by wet-chemical precipitation method. HT in the presence of ambient saturated water steam pressure with variation in the temperature and processing time for the powder of SrHA led to following outcomes.

1. With an increase in the processing time, the temperature needed for a transition from an amorphous to crystalline state decreased from 150 to $120^{\circ} \mathrm{C}$.

2. The XRD pattern showed $\mathrm{Ca}_{2} \mathrm{Sr}_{8}\left(\mathrm{PO}_{4}\right)_{6}(\mathrm{OH})_{2}$ with a trace of $\mathrm{Sr}$-apatite modifications after crystallization. 
Thus, HT in the presence of ambient saturated water steam could be utilized as an alternative method for modification of calcium phosphates at lower processing temperature in contrast to conventional structure modification methods.

\section{Funding}

Conducted research falls under the activities of the Refined Step project, PIRSES-GA2013- 612691 described in www.createyourbiomaterial.eu.

\section{References}

[1] Dorozhkin, S. V. and Epple, M. (2002). Biological and medical significance of calcium phosphates. Angewandte Chemie - International Edition, vol. 41, no. 17. pp. 31303146.

[2] Rangavittal, N., Landa-Cánovas, A. R., González-Calbet, J. M., et al. (2000). Structural study and stability of hydroxyapatite and beta-tricalcium phosphate: Two important bioceramics. Journal of Biomedical Materials Research, vol. 51, no. 4, pp. 660-668.

[3] Yu, H., Zhang, H., Wang, X., et al. (2007). Local structure of hydroxy-peroxy apatite: A combined XRD, FT-IR, Raman, SEM, and solid-state NMR study. Journal of Physics and Chemistry of Solids, vol. 68, no. 10, pp. 1863-1871.

[4] Abd El-Fattah, H., Helmy, Y., El-Kholy, B., et al. (2010). In vivo animal histomorphometric study for evaluating biocompatibility and osteointegration of nanohydroxyapatite as biomaterials in tissue engineering. Journal of the Egyptian National Cancer Institute, vol. 22, no. 4, pp. 241-250.

[5] Noda, I., Miyaji, F., Ando, Y., et al. (2010). Next generation antibacterial hydroxyapatite coating: antibacterial activity of ag ions in serum. Bioceramics Development and Applications, vol. 1, pp. 1-3.

[6] Terra, J., Dourado, E. R., Eon, J.-G., et al. (2009). The structure of strontiumdoped hydroxyapatite: An experimental and theoretical study. Physical Chemistry Chemical Physics, vol. 11, no. 3, pp. 568-577.

[7] Grynpas, M. D., Hamilton, E., Cheung, R., et al. (1996). Strontium increases vertebral bone volume in rats at a low dose that does not induce detectable mineralization defect. Bone, vol. 18, no. 3, pp. 253-259.

[8] P. J. Marie, P. Ammann, G. Boivin, and C. Rey, "Mechanisms of action and therapeutic potential of strontium in bone," Calcified Tissue International, vol. 69, no. 3. pp. 121$129,2001$. 
[9] Dahl, S. G., Allain, P., Marie, P. J., et al. (2001). Incorporation and distribution of strontium in bone. Bone, vol. 28, no. 4, pp. 446-453.

[10] Gopi, D., Nithiya, S., Kavitha, L., et al. (2012). Amino acid-assisted synthesis of strontium hydroxyapatite bone cement by a soft solution freezing method. Bulletin of Materials Science, vol. 35, no. 7, pp. 1195-1199.

[11] Sakai, A., Valanezahad, A., Ozaki, M., et al. (2012). Preparation of Sr-containing carbonate apatite as a bone substitute and its properties. Dental Materials Journal, vol. 31, no. 2, pp. 197-205.

[12] Yang, C. W. and Lui, T. S. (2009). Kinetics of hydrothermal crystallization under saturated steam pressure and the self-healing effect by nanocrystallite for hydroxyapatite coatings. Acta Biomaterialia, vol. 5, no. 7, pp. 2728-2737.

[13] Meguro, K. and Ikeya, M. (1992). Stabilization of radicals by doping from aqueous solutions into crystals of hydroxyapatite. Japanese Journal of Applied Physics, vol. 31, no. 5, p. 1353.

[14] Zhao, H., Li, X., Wang, J., et al. (2000). Characterization of peroxide ions in hydroxyapatite lattice. Journal of Biomedical Materials Research, vol. 52, no. 1, pp. 157-163.

[15] Gross, K. A., Komarovska, L., and Viksna, A. (2013). Efficient zinc incorporation in hydroxyapatite through crystallization of an amorphous phase could extend the properties of zinc apatites. Journal of the Australian Ceramic Society, vol. 49, no. 2, pp. 129-135.

[16] Kavitha, M., Subramanian, R., Vinoth, K. S., et al. (2015). Optimization of process parameters for solution combustion synthesis of Strontium substituted Hydroxyapatite nanocrystals using Design of Experiments approach. Powder Technology, vol. 271, pp. 167-181.

[17] Regnier, P., Lasaga, A. C., Berner, R. A., et al. (1994). Mechanism of C03-substitution in carbonate-fluorapatite: Evidence from FTIR spectroscopy, 13 C NMR, and quantum mechanical calculations. American Mineralogist, vol. 79, pp. 809-818. 